\title{
Leucine Degradation in Cell-Free Extracts of Skeletal Muscle
}

\author{
By RICHARD ODESSEY* $\dagger$ and ALFRED L. GOLDBERG $\ddagger$ \\ †Department of Physiology, University of Virginia Medical Center, Charlottesville, VA 22901, and \\ $\ddagger$ Department of Physiology, Harvard Medical School, Boston, MA 02115, U.S.A.
}

(Received 14 September 1978)

\begin{abstract}
Since skeletal muscle is the major site in the body for oxidation of leucine, isoleucine and valine, the pathway and control of leucine oxidation were investigated in cell-free preparations of rat muscle. Leucine was found to be transaminated to 4-methyl-2-oxopentanoate, which was then oxidatively decarboxylated. On differential centrifugation $70-80 \%$ of the transaminase activity was recovered in the soluble fraction of the cell, and the remaining amount in the mitochondrial fraction. The transaminase, from both fractions had similar $\mathrm{pH}$ optima and both were markedly inhibited by $\mathrm{Ca}^{2+}$. Thus changes in cellular $\mathrm{Ca}^{2+}$ concentration may regulate transaminase activity. Both transaminases had a much higher affinity for 2-oxoglutarate than for pyruvate. Therefore the utilization of amino groups from leucine for the biosynthesis of alanine in muscle [Odessey, Khairallah \& Goldberg (1974) J. Biol. Chem. 249, 7623-7629] in vivo involves transamination with 2-oxoglutarate to produce glutamate, which is then transaminated with pyruvate to produce alanine. The dehydrogenase activity assayed by the decarboxylâtion of methyl-2oxo $\left[1-{ }^{14} \mathrm{C}\right]$ pentanoate was localized exclusively in the fraction containing mitochondria and required $\mathrm{NAD}^{+}, \mathrm{CoA}$ and thiamin pyrophosphate for optimal activity. Measurements of competitive inhibition suggested that the oxo acids of leucine, isoleucine and valine are all decarboxylated by the same enzyme. The enzyme activity was decreased by $90 \%$ upon freezing or sonication and was stimulated severalfold by $\mathrm{Mg}^{2+}, \mathrm{K}^{+}$and phosphate ions. In addition, it was markedly inhibited by ATP, but not by non-metabolizable analogues. This observation suggests that splitting of ATP is required for inhibition. The oxidative decarboxylation of 4-methyl-2-oxopentanoate by the dehydrogenase appears to be the rate-limiting step for leucine oxidation in muscle homogenates and also in intact tissues. In fact, rat muscles incubated with $\left[1-{ }^{14} \mathrm{C}\right]$ leucine release $1-{ }^{14} \mathrm{C}$-labelled oxo acid into the medium at rates comparable with the rate of decarboxylation. Intact muscles also released the oxo acids of $\left[1-{ }^{14} \mathrm{C}\right]$ valine or $\left[1-{ }^{14} \mathrm{C}\right]$ isoleucine, but not of other amino acids. These findings suggest that muscle is the primary source of the branched-chain oxo acids found in the blood.
\end{abstract}

Skeletal muscle rapidly degrades leucine, isoleucine and valine, and this tissue is probably the major site for the degradation of these amino acids in the organism (Odessey \& Goldberg, 1972; Chang \& Goldberg, 1978a,b; Adibi, 1976; Goldberg \& Chang, 1978). Diverse physiological conditions such as starvation, diabetes, and hypophysectomy markedly enhance the catabolism of these amino acids by isolated muscles (Goldberg \& Odessey, 1972; Odessey, 1973; Buse et al., 1973, 1975; Goldberg \& Chang, 1978). The oxidation of leucine may provide appreciable ATP to the muscle in starvation (Chang \& Goldberg, 1978b) and leads to decreased oxidation of glucose (Chang \& Goldberg, 1978c). The degradation of isoleucine and valine probably does not provide significant energy, but can

* To whom reprint requests should be sent. supply intermediates in the tricarboxylic acid cycle and the carbon skeletons used in glutamine synthesis (Chang \& Goldberg, 1978b,c). In addition, the rapid degradation of the branched-chain amino acids provides the amino groups of the alanine and glutamine that are synthesized and released by muscle in large amounts (Odessey et al., 1974; Chang \& Goldberg, 1978a; Felig, 1975; Ruderman, 1975). The metabolism of leucine in muscle is also of special interest since this amino acid, and no other one, somehow promotes protein synthesis and retards protein breakdown in isolated muscle (Fulks et al., 1975; Buse \& Reid, 1976; Goldberg \& Chang, 1978).

Most biochemical studies of the degradative pathway for branched-chain amino acids have focused on the liver and kidney (Aki et al., 1968; Ichihara et al., 1967), although physiological evidence (Odessey \& Goldberg, 1972; Goldberg \& Odessey, 
1972; Odessey, 1973; Miller, 1961; Goldberg \& Chang, 1978; Buse et al., 1973, 1975; Buse \& Reid, 1976) indicates that the rate and control of this process in such tissues differ markedly from those in muscle. Previous studies of incubated rat diaphragm (Odessey \& Goldberg, 1972; Goldberg \& Odessey, 1972; Odessey, 1973; Buse et al., 1973) have indicated that either transamination or decarboxylation is the rate-limiting step in leucine degradation. The activity of one of these reactions is stimulated by starvation, diabetes and hypophysectomy (Goldberg \& Odessey, 1972; Odessey, 1973; Goldberg \& Chang, 1978; Buse et al., 1973). Although several studies have been published on the leucine transaminase activity in skeletal muscle (Ichihara \& Koyama, 1966; Young 1970; Adibi et al., 1975), these investigations have generally failed to correlate this activity with the degradation rate for leucine by the intact muscles, nor have they determined whether this reaction actually is the rate-limiting step. In non-muscle tissues the second enzyme in the pathway for leucine catabolism is 2-oxo acid dehydrogenase, but most workers until recently (Sketcher et al., 1974; Shinnick \& Harper, 1976) have failed to detect this activity in muscle homogenates (Connelly et al., 1968; Dancis et al., 1961; Wohlheuter \& Harper, 1970).

To clarify the biochemical mechanisms controlling leucine oxidation and alanine synthesis in muscle, the properties of the transamination and decarboxylation reactions were examined in cell-free preparations of skeletal muscle. By using separate assays for these two reactions, we have investigated their subcellular distribution, the influence of ions and other factors on these activities, and the rate-limiting reaction in the degradative pathway.

\section{Materials and Methods}

Rats (CD strain) were purchased from the Charles River Laboratories and were provided with Purina laboratory chow and water ad libitum. Generally muscles from rats weighing $60-100 \mathrm{~g}$ were used so that data would be comparable with earlier studies on incubated diaphragms (Odessey \& Goldberg, 1972; Goldberg \& Odessey, 1972). However, no significant difference in the rates of $\mathrm{CO}_{2}$ production were observed when larger animals were used (Odessey, 1973).

\section{Materials}

The dilithium salt of CoA, $\mathrm{NAD}^{+}$, the sodium salt of thiamin pyrophosphate, dithiothreitol, sodium salt of 2-oxoglutaric acid, pyruvic acid, succinic acid, sodium malate, ATP, ADP, AMP, cyclic AMP, GTP, CTP, UTP, L-amino acid oxidase (type IV) and cytochrome $c$ were obtained from Sigma Chemical Co., (St. Louis, MO, U.S.A.). Adenosine $5^{\prime}-[\alpha \beta$ - methylene $]$ diphosphate, adenosine $5^{\prime}$-[ $\beta \gamma$-methylene]diphosphate and adenosine $5^{\prime}$-[ $[\beta \gamma$-imido $]$ diphosphate were obtained from Boehringer Mannheim (New York, U.S.A.). L-Leucine was purchased from Calbiochem (Los Angeles, CA, U.S.A.) and $\mathrm{L}-\left[1-{ }^{14} \mathrm{C}\right]$ leucine was from Schwartz/Mann (Orangeburg, NY, U.S.A.). All reagents were of analytical grade.

\section{Preparation of tissue homogenates}

A modification of the homogenizing buffer of Zak et al. (1970) was found suitable for gentle homogenization of skeletal muscle. Rats were killed by cervical dislocation, and the muscles of the hindlimb including gastrocnemius, soleus and biceps femoris were excised. The tendons and interstitial fat were carefully removed, and the muscle was minced and washed as described (Zak et al., 1970). The tissue was further washed and resuspended in the standard buffer at $4^{\circ} \mathrm{C}$, which contained $0.25 \mathrm{M}$-sucrose, $50 \mathrm{~mm}-\mathrm{KCl}, 5 \mathrm{~mm}-\mathrm{MgCl}_{2}, 5 \mathrm{~mm}-\mathrm{EGTA}$ and $50 \mathrm{~mm}-$ Tris/HCl (pH 7.8). The muscle was then homogenized in a motor-driven loose-fitting (clearance $0.5-1.0 \mathrm{~mm}$ ) glass homogenizer (Kontes Glass Co., Vineland, NJ, U.S.A.) at a speed of about $50 \mathrm{rev} . / \mathrm{min}$. The homogenate was transferred to a tight-fitting (clearance $0.1 \mathrm{~mm}$ ) Ten-Broeck all-glass homogenizer (A. H. Thomas, Philadelphia, PN, U.S.A.) and further homogenized with three or four strokes of the pestle. The volume of the homogenate was adjusted to give a final concentration of about $100 \mathrm{mg}$ of tissue $/ \mathrm{ml}$. This concentration of the homogenate was constant for all enzyme determinations in any experiment.

\section{Cell fractionation}

The muscle homogenate was centrifuged at $800 \mathrm{~g}$ for $5 \mathrm{~min}$ at $4^{\circ} \mathrm{C}$ to remove unbroken cells and myofibrils. After the supernatant was decanted, the pellet was re-extracted in standard buffer and centrifuged as above. To isolate mitochondria, both $800 \mathrm{~g}$ supernatants were centrifuged at $10000 \mathrm{~g}$ for $10 \mathrm{~min}$. The $10000 \mathrm{~g}$ supernatant of the second $800 \mathrm{~g}$ fraction was discarded. The $10000 \mathrm{~g}$ pellet from both fractions were combined, washed once and resuspended in buffer $B(0.25 \mathrm{M}$-sucrose $/ 50 \mathrm{~mm}-\mathrm{KCl} / 10 \mathrm{~mm}$ $\mathrm{MgCl}_{2} / 0.1$ mm-EDTA / 50 mm-Tris/HCl, pH 7.8). Since the mitochondrial enzyme activity was not stable during storage (see the Results section), the $10000 \mathrm{~g}$ pellets were prepared fresh for each experiment.

\section{Preparation of ${ }^{14} \mathrm{C}$-labelled 4-methyl-2-oxopentanoate}

4-Methyl-2-oxo[1- $\left.{ }^{14} \mathrm{C}\right]$ pentanoate was prepared by a modification of the method of Meister (1951). The reaction mixture consisted of $2 \mathrm{~mm}-\left[1-{ }^{14} \mathrm{C}\right]-$ leucine $(1.0 \mathrm{mCi} / \mathrm{mm} \delta \mathrm{l})$, L-amino acid oxidase 
(1.0 unit) and catalase (12000 units) in $10 \mathrm{ml}$ of $10 \mathrm{~mm}$-Tris- $\mathrm{HCl}, \mathrm{pH} 7.5$. The mixture was gassed with $\mathrm{O}_{2} / \mathrm{CO}_{2}(19: 1)$ in a $25 \mathrm{ml}$ flask and incubated at $37^{\circ} \mathrm{C}$ in a gyratory shaker. After $2 \mathrm{~h}$ the reaction was terminated by addition of $1 \mathrm{ml}$ of $1 \mathrm{~m}$-perchloric acid. The protein precipitate was removed by centrifugation and the supernatant further acidified with $0.5 \mathrm{ml}$ of $6 \mathrm{M}-\mathrm{HCl}$. The supernatant was extracted with three equal volumes of freshly opened anaestheticgrade diethyl ether. (Use of chloroform as the extractant gave similar results. The use of anhydrous ether resulted in very low yields of ${ }^{14} \mathrm{C}$-labelled oxo acid, possibly because of the presence of peroxide in this reagent, which can cause the decarboxylation of the oxo acids.) The ether extracts were pooled and re-extracted with $3 \times 3 \mathrm{ml}$ of $0.01 \mathrm{M}-\mathrm{NaOH}$. The $\mathrm{NaOH}$ solution was acidified with $20 \mu \mathrm{l}$ of $6 \mathrm{M}-\mathrm{HCl}$, and $\mathrm{N}_{2} / \mathrm{CO}_{2}(19: 1)$ was bubbled through the solution for $15 \mathrm{~min}$ to drive off radioactive $\mathrm{CO}_{2}$. Any remaining ${ }^{14} \mathrm{CO}_{2}$ was removed under reduced pressure for $15 \mathrm{~min}$ at room temperature.

By using this procedure about $75-90 \%$ of the initial radioactivity was recovered as $1-{ }^{14} \mathrm{C}$-labelled oxo acid. Purity was established by t.l.c. in 2-methylpropan-2-ol/ethyl methyl ketone/water/formic acid $(40: 40: 10: 0.24$, by vol.) (Fink et al., 1963) and in propionic acid/water/butan-1-ol ( $5: 7: 10$, by vol.). At least $95 \%$ of the radioactivity was confined to a spot identified as 2-oxo acid by u.v. fluorescence after reaction with $o$-phenylenediamine (Wieland \& Fischer, 1949). Chromatography of the 2,4-dinitrophenylhydrazone in 3-methylbutan-1-ol/aq. $0.25 \mathrm{M}$ $\mathrm{NH}_{3}(20: 1, \mathrm{v} / \mathrm{v})$ (Dancis et al., 1960) showed the 4methyl-2-oxo[1-14 C]pentanoate to be $99 \%$ pure. In addition, at least $97 \%$ of the 4-methyl-2-oxo[ $\left[1-{ }^{14} \mathrm{C}\right]-$ pentanoate could be recovered as ${ }^{14} \mathrm{CO}_{2}$ after incubation for $1 \mathrm{~h}$ with $2 \mathrm{M}-\mathrm{H}_{2} \mathrm{O}_{2}$, which decarboxylates 2-oxo acids. Finally, the radioactive product could be completely vacuum-evaporated from a frozen acid solution, which is consistent with the low boiling point of 4-methyl-2-oxopentanoate (Meister, 1951).

\section{Enzyme assays}

To assay enzyme activities, $0.5 \mathrm{ml}$ of cell extract was first added to $0.5 \mathrm{ml}$ of assay medium and kept at $4^{\circ} \mathrm{C}$. When the cell extract was prepared in standard buffer, the assay medium consisted of $1.2 \mathrm{mM}-\mathrm{NAD}^{+}$, $0.2 \mathrm{~mm}$-CoA, $1.0 \mathrm{~mm}$-dithiothreitol, $0.133 \mathrm{~mm}$-thiamin pyrophosphate, $5.0 \mathrm{~mm}$-2-oxoglutarate, $1 \mathrm{mM}-\mathrm{NaHCO}_{3}$ and $10 \mathrm{~mm}-\mathrm{Tris} / \mathrm{HCl}, \mathrm{pH}$ 7.8. The concentration of free $\mathrm{Mg}^{2+}$ in these mixtures has been calculated (Portzehl et al., 1964) to be approx. $2.0 \mathrm{~mm}$. When buffer $B$ was used to prepare the cell extract, the assay medium also included $60 \mathrm{~mm}$ $\mathrm{K}_{2} \mathrm{HPO}_{4}$ and $1.1 \mathrm{~mm}-\mathrm{CaCl}_{2}$.

Transaminase activity was measured as the sum of the ${ }^{14} \mathrm{CO}_{2}$ and 4-methyl-2-oxo[1-14 C]pentanoate produced from $\left[1-{ }^{14} \mathrm{C}\right]$ leucine. Except where noted the reaction was started by the addition of $20 \mu$ of $0.5 \mathrm{~mm}-\left[1-{ }^{14} \mathrm{C}\right]$-leucine (10 $\mu \mathrm{M}$ final concn.; $\left.5 \mu \mathrm{Ci} / \mathrm{mol}\right)$ to $1 \mathrm{ml}$ of the assay mixture in $20 \mathrm{ml}$ specimen vials with self-sealing caps. After $10-20 \mathrm{~min}$ at $27^{\circ} \mathrm{C}$, the reaction was terminated by injection of $0.5 \mathrm{ml}$ of $0.5 \mathrm{M}-\mathrm{H}_{2} \mathrm{SO}_{4}$. The ${ }^{14} \mathrm{CO}_{2}$ evolved was collected in polyethylene cups containing $0.3 \mathrm{ml}$ of phenethylamine (Odessey \& Goldberg, 1972). Then the 4methyl-2-oxo[ $\left.1-{ }^{14} \mathrm{C}\right]$ pentanoate formed during incubation was measured as ${ }^{14} \mathrm{CO}_{2}$ liberated after addition of $\mathrm{H}_{2} \mathrm{O}_{2}$. The vial was restoppered with a fresh cup of phenethylamine and injected with $0.5 \mathrm{ml}$ of $30 \%$ $\mathrm{H}_{2} \mathrm{O}_{2}$ to decarboxylate the 4-methyl-2-oxo[ $\left[1-{ }^{14} \mathrm{C}\right]-$ pentanoate. The ${ }^{14} \mathrm{CO}_{2}$ evolved upon addition of peroxide was collected and radioactivity determined as before. This technique also provided information on the dehydrogenase activity of the extracts since it involved measurements of total ${ }^{14} \mathrm{CO}_{2}$ generation and the production of the intermediate 4-methyl-2oxo $\left[1-{ }^{14} \mathrm{C}\right]$ pentanoate. Dehydrogenase activity was also assayed directly by measuring ${ }^{14} \mathrm{CO}_{2}$ production from purified 4-methyl-2-oxo[1-14 $\mathrm{C}]$ pentanoate. 4Methyl-2-oxo[1-14 C]pentanoate (10 $\mu \mathrm{M}$ final concn.) was added to the reaction mixture, which was incubated as described for leucine. After injection of $\mathrm{H}_{2} \mathrm{SO}_{4}$, the ${ }^{14} \mathrm{CO}_{2}$ was collected and radioactivity determined.

The protein content of the homogenate was measured by the biuret method after precipitation with $10 \%(\mathrm{w} / \mathrm{v})$ trichloroacetic acid. Bovine serum albumin (Sigma, fraction V) was used as the standard (Gornall et al., 1949). Cytochrome $c$ reductase was assayed by the method of Green \& Ziegler (1963). Succinate dehydrogenase was assayed as described by Arrigoni \& Singer (1962). Results presented in the Tables and Figures are typical of those obtained in two or more independent experiments. Calculations of the $K_{\mathrm{m}}$ and $V_{\max }$. values for the transaminase and dehydrogenase were made using a non-linear curvefitting method (Cleland, 1967). Statistical significance was determined by using Student's $t$ test.

\section{Chromatography}

For identification of isovaleryl hydroxamate, samples were run on cellulose thin layer plates (Baker Flex) in 4-methylbutan-1-ol/acetic acid/water (4:1:5, by vol.) and butan-1-ol/acetic acid/water $(4: 1: 5$, by vol.). Spots of the hydroxamate were located by spraying with $5 \%(\mathrm{w} / \mathrm{v}) \mathrm{FeCl}_{3}$ in a solution of $95 \%$ (v/v) ethanol and $0.3 \mathrm{M}$-perchloric acid.

\section{Determination of isovaleryl-CoA}

After incubation, samples were deproteinized with $1 \mathrm{M}$-perchloric acid, and isovaleryl-CoA-1 $\mathrm{mg} / \mathrm{ml}$ ) was added as a carrier. The samples were extracted five times with an equal volume of chloroform (this treatment removes $99 \%$ of the 4-methyl-2-oxopentanoate). Hydroxylamine (final concn. $0.37 \mathrm{M}$ ) was added, the 
$\mathrm{pH}$ was adjusted to 7.0 and the mixture was incubated at $40^{\circ} \mathrm{C}$ for $10 \mathrm{~min}$. A sample was taken for radioactivity measurement and assayed for hydroxamate (Notari \& Munson, 1969). To determine the purity of the sample, the remaining mixtures were reacidified and extracted five times with 2 vol. of ethyl acetate. The volume of the samples was diminished and they were chromatographed as described.

\section{Results}

The rate of leucine transamination (i.e. the total production of 4-methyl-2-oxo[1-14 $\mathrm{C}]$ pentanoate and ${ }^{14} \mathrm{CO}_{2}$ ) in the muscle homogenates was linear for approximately $10 \mathrm{~min}$ and then declined (Fig. 1a). At the low leucine concentration $(10 \mu \mathrm{M})$ used in these experiments, the initial rate of substrate utilization has been calculated to be $1.5 \% / \mathrm{min}$. Thus depletion of substrate may have contributed to the diminishing rates of reaction in incubations longer than $10 \mathrm{~min}$. In the $10000 \mathrm{~g}$ supernatant fraction, which contains most of the transaminase activity, but negligible dehydrogenase activity (see below), the rate of transamination was also linear for 10 20 min and then declined (Fig. $1 b$ ).

In contrast with the transamination of leucine, the rate of ${ }^{14} \mathrm{CO}_{2}$ production from $\left[1-{ }^{14} \mathrm{C}\right]$ leucine appeared to increase with time (Fig. 1a). The rate of ${ }^{14} \mathrm{CO}_{2}$ production between 30 and $60 \mathrm{~min}$ was $75 \%$ greater than the initial rate in several experiments. Since this increase occurred concomitantly with an accumulation of oxo acid, it appears likely that leucine was not directly decarboxylated, but was first converted into its oxo acid, which was subsequently decarboxylated.

The production of ${ }^{14} \mathrm{CO}_{2}$ from 4-methyl-2-oxo$\left[1-{ }^{14} \mathrm{C}\right]$ pentanoate was linear for about $30 \mathrm{~min}$ (Fig. 1c). After $30 \mathrm{~min}$ this rate declined, unlike $\mathrm{CO}_{2}$ production from leucine, which increased with time (Fig. 1a). The rate of decarboxylation of 4-methyl-2oxopentanoate by muscle homogenates was severalfold faster than the rate of decarboxylation of leucine. These findings are consistent with the assumption that the degradation of leucine occurs by transamination and subsequent decarboxylation of its oxo acid. Furthermore the initial rate of transamination was severalfold greater than the rate of $\mathrm{CO}_{2}$ production, such that the intermediate 4-methyl-2-oxopentanoate accumulated. Thus decarboxylation of 4-methyl-2-oxopentanoate appeared to be the ratelimiting step in leucine degradation under these conditions (see below). To examine the dependence of the reaction on enzyme concentration, the dehydrogenase and transaminase were measured separately in the isolated $10000 \mathrm{~g}$ supernatant and pellet fractions. All activities varied linearly with protein concentration over a range from $\frac{1}{4}$ to 4 times the usual amount assayed.

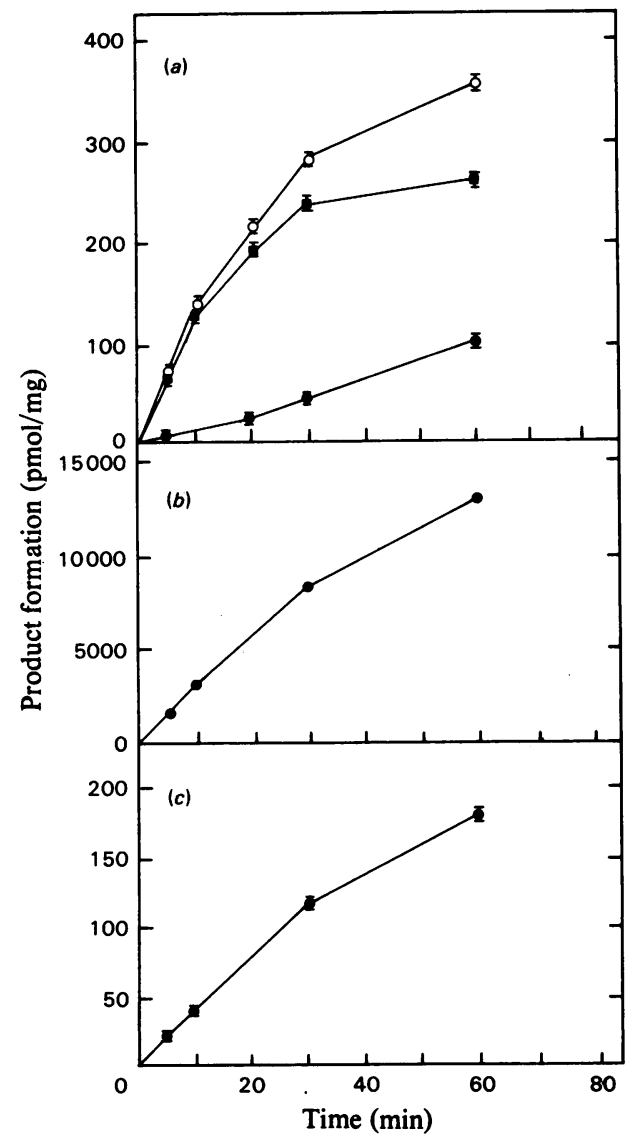

Fig. 1. Transamination and decarboxylation of $\left[1-{ }^{14} C\right]-$ leucine in muscle homogenates (a), transamination of $\left[1-{ }^{14} \mathrm{C}\right]$ leucine in $10000 \mathrm{~g}$ supernatant $(b)$ and decarboxylation of 4-methyl-2-oxo $\left[1-{ }^{14} \mathrm{C}\right]$ pentanoate in homogenates (c)

Muscle homogenates were prepared in buffer B and incubated with $10 \mu \mathrm{M}-\left[1-{ }^{14} \mathrm{C}\right]$ leucine as described in the text. Transaminase activity represents the sum of the ${ }^{14} \mathrm{CO}_{2}$ and the 4-methyl-2-oxo[1- $\left.{ }^{14} \mathrm{C}\right]$ pentanoate production, assayed as described in the Materials and Methods section. $\bullet,{ }^{14} \mathrm{CO}_{2}$ production; $\square$, oxo acid production; $O$, total ${ }^{14} \mathrm{C}$ transaminated. (b) The $10000 \mathrm{~g}$ supernatant was prepared from muscles homogenized in standard buffer and assayed with $100 \mu \mathrm{M}-\left[1-{ }^{14} \mathrm{C}\right]$ leucine. (c) Muscle homogenates prepared in standard buffer were incubated with $10 \mu \mathrm{M}$ 4-methyl-2-oxo[1-14 C]pentanoate. Reactions were terminated by injection of $\mathrm{H}_{2} \mathrm{SO}_{4}$, and the ${ }^{14} \mathrm{CO}_{2}$ liberated from the medium was collected as described in the Materials and Methods section.

Subcellular distribution of enzymes for leucine oxidation

The results in Table 1 indicate that the transaminase and dehydrogenase activities were distributed in 


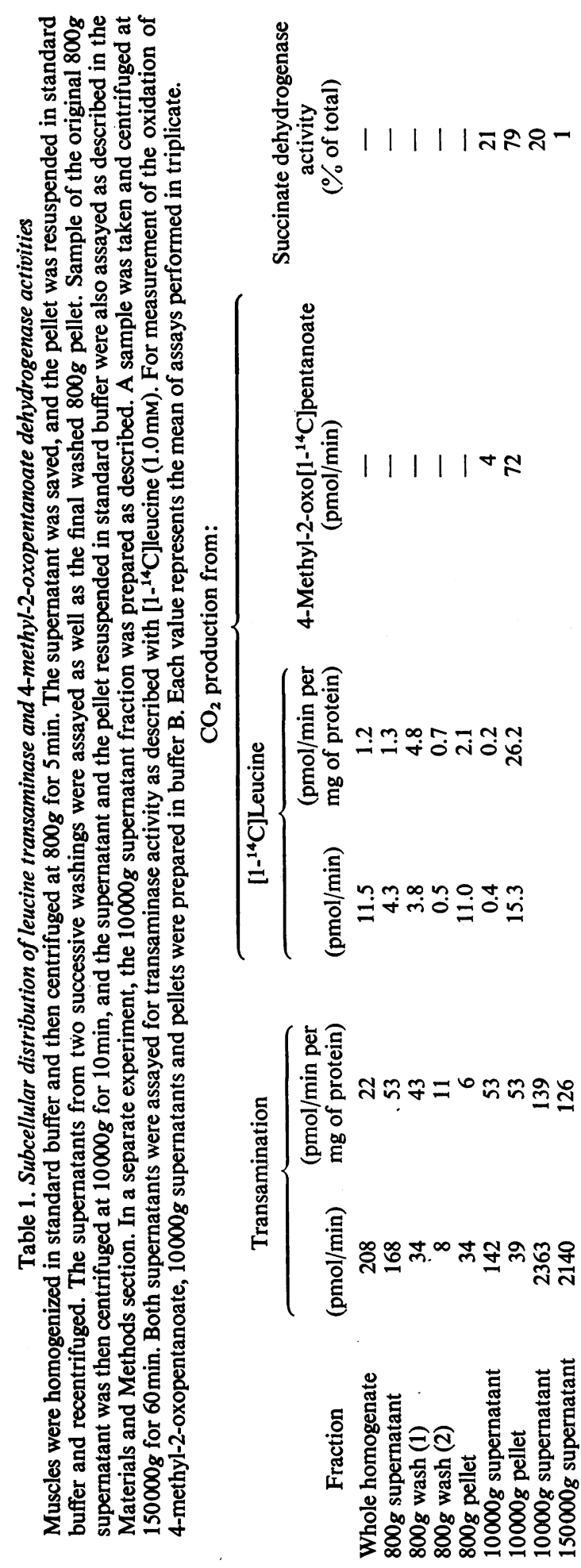

different fractions of the muscle homogenate obtained by centrifugation. When homogenates were prepared with standard buffer, most of the transaminase activity was soluble since $70-80 \%$ of the activity remained in the supernatant after successive centrifugations for $20 \mathrm{~min}$ at $10000 \mathrm{~g}$ or $150000 \mathrm{~g}$ for $60 \mathrm{~min}$ (Table 1). The remaining $20-30 \%$ of the activity was recovered in the $10000 \mathrm{~g}$ pellet. This pellet fraction has been reported to consist mainly of mitochondria (Zak et al., 1970) and was found to contain a higher specific activity of cytochrome $c$ reductase than the supernatant.

Unlike the transaminase, dehydrogenase activity (assayed by the decarboxylation of 4-methyl-2-oxopentanoate or leucine) was found mainly in the $10000 \mathrm{~g}$ mitochondrial pellet and not in the $10000 \mathrm{~g}$ supernatant (Table 1). The transaminase and dehydrogenase activities retained in the $800 \mathrm{~g}$ pellets even after two washings probably are associated with mitochondria entrapped within the myofibrillar complexes or within incompletely disrupted cells.

The $10000 \mathrm{~g}$ pellet contained $80 \%$ of the succinate dehydrogenase activity (Table 1) and thus included most of the mitochondria. This crude centrifugal fraction undoubtedly contains other intracellular membranes as well. However, if either the transaminase or the dehydrogenase were actually localized in a 'microsomal' fraction, significant activity should also be found in the fraction sedimenting between 10000 and $150000 \mathrm{~g}$. This result was not obtained (Table 1). Thus the enzyme activities in the $10000 \mathrm{~g}$ pellet are probably localized in the muscle mitochondria. This conclusion is consistent with the enzyme distribution reported in other tissues (Ichihara \& Koyama, 1966; Aki et al., 1968). Although further investigation with specific membrane markers will be necessary to prove a mitochondrial location, the activities of the dehydrogenase and transaminase in the $10000 \mathrm{~g}$ pellet will henceforth be referred to as mitochondrial subject to the caveat stated above.

It is interesting that the mitochondrial pellet had 3 -fold the dehydrogenase activity of the $800 \mathrm{~g}$ supernatant from which it was isolated. Furthermore, the sum of the ${ }^{14} \mathrm{CO}_{2}$ production by the $800 \mathrm{~g}$ supernuiant, washes and pellet exceeded that of the parent homogenate. By contrast, the total transaminase activities of the $800 \mathrm{~g}$ and the $10000 \mathrm{~g}$ pellets were approximately equal to the activity of the parent fraction. These results also suggest that the supernatant fraction contains an inhibitory factor(s) for the mitochondrial dehydrogenase.

\section{Properties of the transaminase and dehydrogenase} reactions

(a) Cofactor requirements, Production of 4-methyl2-oxopentanoate from leucine by the dialysed supernatant or washed mitochondrial pellets decreased by 
Table 2. Kinetic constants for leucine transamination with different substrates

Transaminase activities of mitochondrial and $10000 \mathrm{~g}$ supernatant fractions were assayed in triplicate in standard buffer (pH 7.8). When oxo acid concentrations were varied, leucine was present at $0.1 \mathrm{~mm}$. Leucine concentrations were varied in the presence of $2.5 \mathrm{~mm}$-oxoglutarate. In most cases the mean activities at four concentrations of substrate (ranging from 0.1 to $10 \mathrm{~mm}$ ) were used. Mitochondrial transaminase activity was assayed at three pyruvate concentrations. The $K_{\mathrm{m}}$ and $V_{\max }$. were calculated by a non-linear regression analysis (Cleland, 1967).

\begin{tabular}{|c|c|c|c|c|}
\hline \multirow[b]{2}{*}{ Substrate } & \multicolumn{2}{|c|}{ Supernatant activity } & \multicolumn{2}{|c|}{ Mitochondrial activity } \\
\hline & $\underset{(\mathrm{mM})}{K_{\mathrm{m}}}$ & $\begin{array}{c}V_{\max } \\
\text { (pmol/min per } \\
\mathrm{mg} \text { of protein) }\end{array}$ & $\underset{(\mathrm{mM})}{K_{\mathrm{m}}}$ & $\begin{array}{c}V_{\max } \\
\text { (pmol/min per } \\
\text { mg of protein) }\end{array}$ \\
\hline $\begin{array}{l}\text {-Oxoglutarate } \\
\text { yruvate } \\
\text { eucine }\end{array}$ & $\begin{array}{l}0.10 \pm 0.01 \\
3.4 \pm 1.8 \\
0.37 \pm 0.07\end{array}$ & $\begin{array}{c}1030 \pm 18 \\
140 \pm 33 \\
1440 \pm 220\end{array}$ & $\begin{array}{l}0.15 \pm 0.01 \\
0.44 \pm 0.08 \\
0.48 \pm 0.06\end{array}$ & $\begin{array}{c}2990 \pm 300 \\
2070 \pm 86 \\
16600 \pm 400\end{array}$ \\
\hline
\end{tabular}

Table 3. Cofactor requirements for leucine decarboxylation and 4-methyl-2-oxopentanoate dehydrogenase Muscles were homogenized and dialysed for $2 \mathrm{~h}$ in standard buffer and assayed for ${ }^{14} \mathrm{CO}_{2}$ production from $\left[1-{ }^{14} \mathrm{C}\right] l$ eucine and 4-methyl-2-oxo[ $\left[1-{ }^{14} \mathrm{C}\right]$ pentanoate. Washed $10000 \mathrm{~g}$ pellets were suspended in buffer B and assayed for dehydrogenase activity. DLCarnitine hydrochloride (Sigma) was added at a concentration of $1 \mathrm{~mm}$. NADH concentration was $0.25 \mathrm{~mm}$ and isovaleryl-CoA was $0.2 \mathrm{~mm}$. For these last two experiments, media contained no added phosphate or $\mathrm{Ca}^{2+}$, and 4-methyl-2-oxo[1- $\left.{ }^{14} \mathrm{C}\right]$ pentanoate was present at a concentration of $20 \mu \mathrm{M}$. Each value is the mean \pm S.E.M. of measurements made in triplicate. * Significantly different from control $(P<0.01)$.

$\begin{array}{ccc}\begin{array}{c}\text { Compound } \\ \text { omitted } \\ (-)\end{array} \\ \begin{array}{c}(-) \\ \text { or added }(+)\end{array} & \begin{array}{c}\text { Leucine } \\ \text { decarboxylation } \\ \text { in } \\ \text { homogenate }\end{array} & \begin{array}{c}\text { Dehydrogenase } \\ \text { in } \\ 10000 \mathrm{~g} \text { pellet }\end{array} \\ \text { ne } & 100 & 100 \\ \text { ithiothreitol } & 75 \pm 2^{*} & - \\ \text { AD }^{+} & 96 \pm 2 & 53 \pm 3^{*} \\ \text { OA }_{\text {hiamin pyro- }} & 99 \pm 10 & 10 \pm 2^{*} \\ \text { phosphate } & 95 \pm 10 & 66 \pm 13^{*} \\ \text { CO }^{-} & 85 \pm 1^{*} & - \\ \text { xoglutarate } & 32 \pm 3^{*} & 114 \pm 18 \\ \text {-Carnitine } & 99 \pm 2 & 87 \pm 9 \\ \text { ADH } & - & 65 \pm 11^{*} \\ \text { sovaleryl-CoA } & - & 80 \pm 5^{*}\end{array}$

$97 \%$ in the absence of 2-oxoglutarate. In addition, ${ }^{14} \mathrm{C}$-labelled oxo acid production was not stimulated by incubation with $\mathrm{O}_{2}$, nor was deamination inhibited by $\mathrm{N}_{2}$. These data argue against the existence of an L-amino acid oxidase in muscle. Thus transamination is the major and probably the only pathway for leucine deamination in muscle homogenates.
Both mitochondrial and supernatant transaminases were found to have a $K_{\mathrm{m}}$ of about $0.4 \mathrm{~mm}$ for lucine (Table 2) and a $K_{\mathrm{m}}$ of about $0.1 \mathrm{~mm}$ for oxoglutarate. By contrast, the $K_{\mathrm{m}}$ of the supernatant transaminase for pyruvate was over $3 \mathrm{~mm}$ and saturating concentrations of pyruvate supported only one-tenth of the maximal rate of leucine transamination. Such high concentrations of pyruvate $(2.5 \mathrm{~mm})$ inhibited the transamination of leucine with 2-oxoglutarate. The $K_{\mathrm{m}}$ of the mitochondrial transaminase for pyruvate was lower than that of the supernatant enzyme, but still higher than the $K_{\mathrm{m}}$ for 2-oxoglutarate (Table 2). Since the possibility existed that the reaction of pyruvate with the particulate transaminase was due to its conversion into 2oxoglutarate, the activity was remeasured in the presence of arsenite $(1 \mathrm{mM})$ and $\mathrm{NaCN}(1 \mathrm{~mm})$ to block pyruvate dehydrogenase. Under these conditions, the activity was barely detectable at $1 \mathrm{~mm}$ pyruvate, whereas $2.5 \mathrm{~mm}$-pyruvate supported a rate of transamination that was only $5 \%$ of the maximal rate with 2-oxoglutarate. In addition, detergent treatment, which stimulates transamination with 2-oxoglutarate 2-3-fold (Table 6), did not enhance transamination with pyruvate. These data suggest that pyruvate is probably not a co-substrate for leucine transamination, but high concentrations may catalyse a small amount of non-specific transamination, with other transaminases present in the cell. Oxaloacetate (results not shown) was only $10 \%$ as effective as 2-oxoglutarate in stimulating transamination. Thus, of the major oxo acids in muscle, oxoglutarate is the preferred amino acceptor for leucine transamination.

$\mathrm{CoA}, \mathrm{NAD}^{+}$and thiamin pyrophosphate were necessary for maximal activity of 4-methyl-2-oxopentanoate dehydrogenase in the washed $10000 \mathrm{~g}$ pellet (Table 3). The concentrations of these cofactors used in all other experiments were at least 2 times that required to give maximal dehydrogenase activity. The coenzymes were not required for the 
decarboxylation of leucine in dialysed crude homogenates, probably because of a failure of the dialysis to remove completely these cofactors. The addition of carnitine, a cofactor in leucine oxidation subsequent to the decarboxylation step (Solberg \& Bremer, 1970), had no significant effect on the dedecarboxylation of leucine in whole homogenates or on the dehydrogenase activity of washed mitochondrial pellets. The dehydrogenase activity is

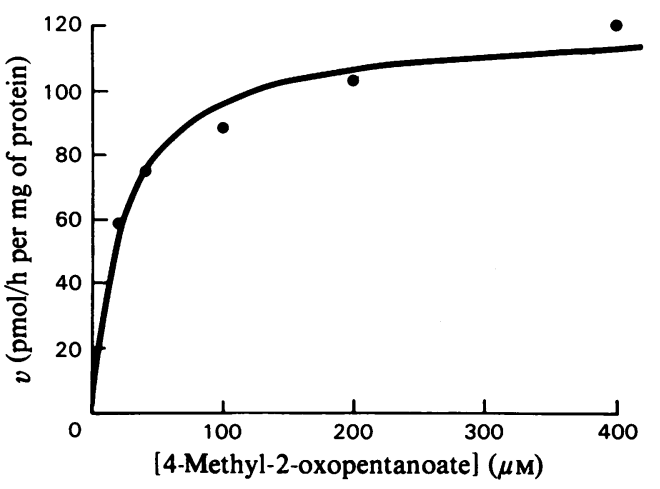

Fig. 2. Kinetics of 4-methyl-2-oxopentanoate dehydrogenase in isolated mitochondria

Isolated mitochondria were incubated in buffer $\mathbf{B}$ without added phosphate or $\mathrm{Ca}^{2+}$. 4-Methyl-2oxo[1-14 C]pentanoate was added at the concentrations shown and incubated for $30 \mathrm{~min} .{ }^{14} \mathrm{CO}_{2}$ was collected as described. Each point represents the mean of three measurements. Calculations using the non-linear curve fitting (Cleland, 1967) indicated that $K_{\mathrm{m}}=24 \pm 5 \mu \mathrm{M}$ and $V_{\max .}=119 \pm 6 \mathrm{pmol} / \mathrm{h}$ per $\mathrm{mg}$. inhibited by the end products of the reaction, NADH and isovaleryl-CoA. Under optimal conditions, the dehydrogenase activity was found to have a $K_{\mathrm{m}}$ for 4-methyl-2-oxopentanoate that varied from 20 to $30 \mu \mathrm{M}$ (Fig. 2). Similar experiments on whole-muscle homogenates yielded a $V_{\text {max. }}$ of $55 \mathrm{pmol} / \mathrm{min}$ per $\mathrm{mg}$ of protein, which was still 8 -fold slower than the maximal rate of leucine transamination.

(b) Stoicheiometry. To determine the reaction products and stoicheiometry, isolated mitochondria pellets were incubated with 4-methyl-2-oxo[U- $\left.{ }^{14} \mathrm{C}\right]-$ pentanoate prepared as described for 4-methyl-2oxo[1-14 C]pentanoate. The ${ }^{14} \mathrm{CO}_{2}$ liberated was measured. After incubation the reaction medium was analysed for $\left[{ }^{14} \mathrm{C}\right]$ isovaleryl-CoA as described in the Materials and Methods section. The reaction product after conversion into the hydroxamate ran identically with isovaleryl hydroxamate in the two solvent systems utilized. In addition, the amount of labelled isovaleryl-CoA accumulated during the reaction (after correction for the blank) accounted for $92 \%$ of the amount expected from the amount of ${ }^{14} \mathrm{CO}_{2}$ production.

(c) Substrate specificity. Substrate specificity of 4-methyl-2-oxopentanoate dehydrogenase was investigated indirectly by measuring the ability of various oxo acids to inhibit the decarboxylation of 4-methyl-2-oxo[1-14 C]pentanoate. The oxo acids were present at 10 times the concentration of 4methyl-2-oxopentanoate. As shown in Table 4, the two branched-chain oxo acids derived from isoleucine and valine competitively inhibited decarboxylation of 4-methyl-2-oxopentanoate. Furthermore, the low inhibitory constants $\left(K_{i}\right)$ were approximately equal to the $K_{\mathrm{m}}$ of the dehydrogenase for 4-methyl-2-

Table 4. Effect of unlabelled oxo acids on the decarboxylation of $1-{ }^{14} \mathrm{C}$-labelled branched-chain oxo acids Mitochondria were isolated in standard buffer with $\mathrm{Mg}^{2+}$ concentration lowered to $0.5 \mathrm{~mm}$. Assay buffer (containing $0.4 \mathrm{~mm}$-amino-oxyacetate to prevent transamination of the oxo acids) was added and the $\mathrm{Mg}^{2+}$ was adjusted to $5 \mathrm{~mm}$. The mixture was preincubated at $27^{\circ} \mathrm{C}$ for $1 \mathrm{~h}$. The reaction was started by the addition of the appropriate unlabelled oxo acid $(200 \mu \mathrm{M})$ followed by the addition of 4-methyl-2-oxo[1-14 C]pentanoate at the concentration shown. After $5 \mathrm{~min}$ the reaction was terminated by the addition of $1 \mathrm{M}$-perchloric acid and the ${ }^{14} \mathrm{CO}_{2}$ was collected. When pyruvate and 2-oxoglutarate were studied $\mathrm{NaCN}(1 \mathrm{~mm})$ was also added. This compound had no effect on the kinetic parameters of the control. The kinetic parameters were estimated by non-linear regression analysis (Cleland, 1967) of five concentrations of radioactive substrate (varied from 10 to $200 \mu \mathrm{M}$ ) assayed in triplicate in at least two independent experiments.

*Significant effect of addition $(P<0.01)$.

Substrate

4-Methyl-2-oxo[1-14 C]pentanoate

4-Methyl-2-oxopentanoate

3-Methyl-2-oxopentanoate

Pyruvate

2-Oxoglutarate

3-Methyl-2-oxo[1-14 C]pentanoate

4-Methyl-2-oxopentanoate

3-Methyl-2-oxopentanoate
$K_{\mathrm{m}}$

$25 \pm 4$

$191 \pm 58^{*}$

$175 \pm 41 *$

$23 \pm 5$

$24 \pm 4$

$26 \pm 8$

$30 \pm 3$

$194 \pm 30^{*}$

$195 \pm 63^{*}$

$V_{\max }$
$(\mathrm{pmol} / \mathrm{min}$ per
$154 \pm 9$
$170 \pm 36$
$146 \pm 24$
$471 \pm 34$
$517 \pm 47$
$422 \pm 49$
$116 \pm 13$
$131 \pm 22$
$128 \pm 26$

$\boldsymbol{K}_{1}$ $(\mu \mathrm{M})$

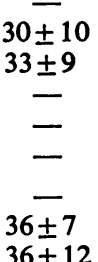


Table 5. Effects of $\mathrm{Ca}^{2+}, \mathrm{Mg}^{2+}$ and phosphate on leucine transamination by supernatant and mitochondrial fractions The $10000 \mathrm{~g}$ supernatant fraction was prepared and dialysed for $2 \mathrm{~h}$ in standard buffer containing $0.1 \mathrm{mM}$-EDTA without added $\mathrm{Mg}^{2+}$. The $10000 \mathrm{~g}$ pellets were also washed in standard buffer without $\mathrm{Mg}^{2+}$. To these mixtures $\mathrm{MgCl}_{2}, \mathrm{CaCl}_{2}$ and $\mathrm{K}_{2} \mathrm{HPO}_{4}$ were added as indicated. The lower $(\leqslant 2 \mu \mathrm{M}) \mathrm{Ca}^{2+}$ concentrations were obtained by using Ca ${ }^{2+} / \mathrm{EGTA}^{2}$ buffers (Portzehl et al., 1964). Each value represents the mean \pm S.E.M. of assay performed in triplicate.

Ion concn. (M)

$\begin{array}{ccc}\mathrm{Mg}^{2+} & \mathrm{Ca}^{2+} & \mathrm{PO}_{4}{ }^{3-} \\ 0 & 0 & 0 \\ 0 & 0 & 3 \times 10^{-2} \\ 5 \times 10^{-3} & 0 & 0 \\ 5 \times 10^{-3} & 1.9 \times 10^{-8} & 0 \\ 5 \times 10^{-3} & 1.7 \times 10^{-7} & 0 \\ 5 \times 10^{-3} & 3.5 \times 10^{-7} & 0 \\ 5 \times 10^{-3} & 1.6 \times 10^{-6} & 0 \\ 5 \times 10^{-3} & 1.0 \times 10^{-4} & 0 \\ 5 \times 10^{-3} & 0.50 \times 10^{-3} & 0 \\ 0 & 0.5 \times 10^{-3} & 0\end{array}$

Transaminase activity $(\%)$

\begin{tabular}{cc}
\hline Supernatant & Mitochondrial \\
$100 \pm 5$ & $100 \pm 4$ \\
$101 \pm 7$ & $99 \pm 2$ \\
$101 \pm 3$ & $100 \pm 5$ \\
$82 \pm 10$ & - \\
$60 \pm 19$ & - \\
$25 \pm 11$ & - \\
$13 \pm 7$ & - \\
$5 \pm 0$ & - \\
$5 \pm 0$ & - \\
$10 \pm 1$ & $109 \pm 15$
\end{tabular}

Table 6. Effect of $\mathrm{Ca}^{2+}$ on leucine transamination in detergent-disrupted mitochondria

Mitochondria were isolated in standard buffer. The mitochondria were diluted to $0.3 \mathrm{mg} / \mathrm{ml}$ with $50 \mathrm{~mm}$ Tris/ $\mathrm{HCl}$ buffer, pH 7.8, containing $1 \mathrm{~mm}-\mathrm{NaHCO}_{3}$, $2.5 \mathrm{~mm}$-2-oxoglutarate and $1.0 \mathrm{~mm}$-sodium arsenite. When present, free $\mathrm{Ca}^{2+}$ was $0.5 \mathrm{~mm}$ and Triton $\mathrm{X}-100$ was $5 \mathrm{mg} / \mathrm{ml}$. Transaminase activity was assayed by adding $\left[1-{ }^{14} \mathrm{C}\right]$ leucine $(0.4 \mathrm{~mm})$ and incubating for $10 \mathrm{~min}$. Each value represents the mean \pm S.E.M. of triplicate samples. ${ }^{*} P<0.01$ versus control; ${ }^{* *} P<0.01$ versus detergent alone.

$\begin{array}{ccc}\begin{array}{c}\text { Activity } \\ \text { (pmol/min per } \\ \text { mg of protein) }\end{array} & \begin{array}{c}\text { Effect of } \\ \mathrm{Ca}^{2+} \\ (\%)\end{array} & \begin{array}{c}\text { Effect of } \\ \text { detergent } \\ (\%)\end{array} \\ 2815 \pm 750 & - & - \\ 3298 \pm 286 & +17 & - \\ 7411 \pm 119^{*} & - & +163 \\ 4012 \pm 328^{* *} & -46 & +22\end{array}$

oxopentanoate. It thus appears likely that all these branched-chain oxo acids probably can serve as substrates for the same enzyme.

To test this hypothesis, the decarboxylation of 3-methyl-2-oxo[1-14 C]valerate, the oxo acid of valine, was studied. The $K_{\mathrm{m}}$ for this substrate was not significantly different from its $K_{1}$ calculated from the inhibition of 4-methyl-2-oxopentanoate oxidation (Table 4). In addition, both 4-methyl-2-oxopentanoate and 3-methyl-2-oxopentanoate also completely inhibited the decarboxylation of 3-methy-2oxovalerate, the oxo acid of valine. The calculated $K_{\mathrm{i}}$ for 4-methyl-2-oxopentanoate is not significantly different from its $K_{\mathrm{m}}$. Since the branched-chain oxo acids competitively inhibit the oxidation of each other with affinities that are apparently equal to their affinities as substrates for the dehydrogenase, it is most likely that the site of inhibition and the catalytic site are one and the same. These findings are most simply accounted for by a single dehydrogenase that catalyses the decarboxylation of all three branched-chain oxo acids. This enzyme appears distinct from the dehydrogenases that oxidize pyruvate or 2-oxoglutarate, since these compounds did not inhibit the decarboxylation of 4-methyl-2oxopentanoate (Table 4).

(d) Influence of ions. Neither phosphate nor $\mathrm{Mg}^{2+}$ ions had any significant effect on the transamination of leucine by $10000 \mathrm{~g}$ supernatants or pellets (Table 5). However, $\mathrm{Ca}^{2+}$ ions inhibited markedly the activity of the supernatant transaminase. The soluble transaminase was sensitive to very low concentrations of $\mathrm{Ca}^{2+}$. Thus an EGTA-buffered solution of $0.02 \mu \mathrm{M}-\mathrm{Ca}^{2+}$ resulted in an $18 \%$ inhibition and $2 \mu \mathrm{M}$ in an $87 \%$ inhibition of transaminase activity. These results (Table 5) indicate a half-maximal inhibition at approximately $0.2 \mu \mathrm{M}$.

Unlike the soluble enzyme, the transaminase from the mitochondrial fraction was insensitive to exogenously added $\mathrm{Ca}^{2+}$ ions (Table 5). However, since mitochondria contain high amounts of calcium, the experiment was repeated with mitochondrial pellets disrupted with a high concentration of Triton $\mathrm{X}-100(5 \mathrm{mg} / \mathrm{ml} ; 17 \mathrm{mg} / \mathrm{mg}$ of protein $)$. As shown in Table 6, addition of $\mathrm{Ca}^{2+}$ resulted in a $50 \%$ inhibition of transaminase activity in detergent-treated preparations. Thus, both soluble and particulate forms of the transaminase are inhibited by $\mathrm{Ca}^{2+}$. Table 6 also shows that, in the absence of $\mathrm{Ca}^{2+}$, addition of detergent stimulated transamination almost 3-fold. This effect appears to be caused by a lowering of the free $\mathrm{Ca}^{2+}$ concentration near the active site rather than removal of a permeability 
barrier, since in the presence of $\mathrm{Ca}^{2+}$ the detergent has no significant stimulatory effect. This conclusion is supported by additional experiments showing that, in the absence of $\mathrm{Ca}^{2+}$, Triton X-100 addition still stimulates activity 2-3-fold even with saturating concentration of leucine $(5.0 \mathrm{~mm})$ and oxoglutarate (2.5 mM).

Both $\mathrm{Mg}^{2+}$ and $\mathrm{Ca}^{2+}$ were necessary for maximal decarboxylation of 4-methyl-2-oxo[1-14 C]pentanoate by the washed mitochondrial pellet (Table 7). The dehydrogenase was maximally active at $5 \mathrm{~mm}$ $\mathrm{Mg}^{2+}$. $\mathrm{Ca}^{2+}$ ions had much smaller effects on the dehydrogenase activity (Table 7). Saturating concentrations of $\mathrm{Ca}^{2+}$ ions $(0.5 \mathrm{mM})$ increased the activity only $15-30 \%$, both in the presence and in the absence of $\mathrm{Mg}^{2+}$. Table 7 also shows that $\mathrm{K}^{+}$ions had a significant stimulatory effect. Phosphate ions also stimulated the dehydrogenase activity (Table 7); $30 \mathrm{~mm}$ concentrations of phosphate resulted in maximal activity but $2.5 \mathrm{~mm}$-phosphate had no effect. The addition of L-malate, which is known to stimulate

Table 7. Effects of ions on 4-methyl-2-oxopentanoate dehydrogenase

To test the effects of bivalent cations, the washed $10000 \mathrm{~g}$ pellets were suspended in buffer B and assay medium from which $\mathrm{Mg}^{2+}$ and $\mathrm{Ca}^{2+}$ had been omitted and substituted with the bivalent cations indicated (at the same concentration as the ion for which it was substituted). Samples without $\mathrm{Mg}^{2+}$ or $\mathrm{Ca}^{2+}$ also contained 5 mM-EGTA and 5 mM-EDTA. To test the effect of $\mathrm{K}^{+}$removal, sodium salts were substituted for potassium salts. When both $\mathrm{Na}^{+}$and $\mathrm{K}^{+}$were present, the assay mixture was supplemented with $20 \mathrm{~mm}$ $\mathrm{NaCl}$. Similarly, phosphate concentrations in the buffer were varied as indicated. Each assay was performed in triplicate.

\begin{tabular}{|c|c|c|}
\hline Ion added & $\begin{array}{l}\text { Concentration } \\
(\mathrm{mM})\end{array}$ & Activity $(\%)$ \\
\hline $\begin{array}{l}\mathrm{Mg}^{2+} \text { and } \\
\mathrm{Ca}^{2+}\end{array}$ & $\begin{array}{l}5.0 \\
0.5\end{array}$ & 100 \\
\hline $\mathrm{Ca}^{2+}$ only & 0.5 & 15 \\
\hline $\mathrm{Mg}^{2+}$ only & 5.0 & 77 \\
\hline $\begin{array}{c}\mathrm{Mn}^{2+} \text { and } \\
\mathrm{Ca}^{2+}\end{array}$ & $\begin{array}{l}5.0 \\
0.5\end{array}$ & 26 \\
\hline $\begin{array}{c}\mathrm{Mn}^{2+} \text { and } \\
\mathrm{Mg}^{2+}\end{array}$ & $\begin{array}{l}0.5 \\
5.0\end{array}$ & 75 \\
\hline None & - & 8 \\
\hline $\mathrm{K}^{+}$only & 50 & 100 \\
\hline $\begin{array}{c}\mathrm{K}^{+} \text {and } \\
\mathrm{Na}^{+}\end{array}$ & $\begin{array}{l}50 \\
20\end{array}$ & 100 \\
\hline $\mathrm{Na}^{+}$only & 50 & 19 \\
\hline Phosphate only & $\begin{array}{l}30 \\
2.5\end{array}$ & $\begin{array}{r}100 \\
50\end{array}$ \\
\hline $\begin{array}{l}\text { Phosphate and } \\
\text { L-malate }\end{array}$ & $\begin{array}{r}40 \\
2\end{array}$ & 75 \\
\hline None & - & 50 \\
\hline $\begin{array}{l}\text { Phosphate and } \\
\text { arsenate }\end{array}$ & $\begin{array}{l}30 \\
1.2\end{array}$ & 9 \\
\hline
\end{tabular}

a number of mitochondrial transport systems (Chappell, 1968), in the presence of phosphate actually inhibited dehydrogenase activity.

(e) Stability and $p H$-dependence. The relative stabilities of the transaminase and dehydrogenase differed dramatically. Dehydrogenase activity was decreased $90 \%$ by sonication. Freezing (for 1 day) and thawing decreased dehydrogenase activity by $90 \%$, and suspending the $10000 \mathrm{~g}$ pellets in glycerol failed to preserve this activity. By contrast, sonication of the whole homogenates or freezing the $10000 \mathrm{~g}$ supernatant for 1 month had no significant effect on the transaminase activity. Freezing, however, did result in a $30 \%$ loss of transaminase activity from the pellet.

The decarboxylation of leucine in whole homogenates and washed $10000 \mathrm{~g}$ pellets had a pH optimum of 7.8. The same $\mathrm{pH}$ optimum was also found for the dehydrogenase (assayed with 4-methyl-2oxo[ $\left[1-{ }^{14} \mathrm{C}\right]$ pentanoate), but the transaminase activity was maximal at a higher $\mathrm{pH}(8.2-8.6)$. This difference in $\mathrm{pH}$ optima was reproducible and is considered significant. The correspondence between the $\mathrm{pH}$ optimum for decarboxylation of leucine and that for oxidation of 4-methyl-2-oxopentanoate supports the earlier conclusion that the rate of leucine oxidation in muscle extracts is limited by the dehydrogenase activity.

(f) Effects of nucleotide phosphates. The cofactor requirements and subcellular distribution of the branched-chain oxo acid dehydrogenase resemble those of pyruvate dehydrogenase. Since pyruvate dehydrogenase is regulated by adenine nucleotides via phosphorylation (Chiang \& Sactor, 1975; Linn et al., 1969), the effects of ATP and ADP on dehydrogenase activity were tested. To test the effects of various nucleotide concentrations, appropriate regenerating systems were added to maintain constant concentrations of these nucleotides during the incubations (Table 8). The regenerating systems alone had no effect on enzyme activity. Under these conditions, $0.2 \mathrm{~mm}$-ATP inhibited dehydrogenase activity by almost $90 \%$. A plot of inhibition versus oxo acid concentrations (R. Odessey \& A. L. Goldberg, unpublished results) showed inhibition was purely non-competitive. An equal concentration of ADP inhibited only $50 \%$ (Table 8). It is still unclear whether ADP directly inhibits 4-methyl-2oxopentanoate dehydrogenase, since subsequent analysis has shown that the glucose/hexokinase regenerating system allowed some synthesis of ATP from ADP by the mitochondria. Other nucleotides, including AMP, cyclic AMP, GTP, CTP and UTP, had no significant effect on this activity. In addition, analogues of ATP in which the oxygen atoms of the phosphate ester bonds were substituted by methylene or imido groups did not significantly inhibit activity (Table 8). Unlike the dehydrogenase, leucine trans-

Vol. 178 
Table 8. Effects of nucleotides on 4-methyl-2-oxopentanoate dehydrogenase and leucine transaminase activities of muscle homogenates

Washed $10000 \mathrm{~g}$ pellets and supernatants were prepared in buffer B from homogenates of muscles from fed rats. Phosphocreatine ( $2 \mathrm{mM}$ ) and creatine kinase ( $30 \mathrm{units} / \mathrm{ml}$ ) were used as the ATP-regenerating system. Glucose ( $20 \mathrm{~mm})$ and hexokinase ( $30 \mathrm{units} / \mathrm{ml}$ ) were used as the ADP-regenerating system. Transaminase activity of $10000 \mathrm{~g}$ supernatants was also assayed. The assay medium contained oxoglutarate $(2 \mathrm{mM})$ and EGTA $(2 \mathrm{mM})$, but no added $\mathrm{Ca}^{2+}$ or phosphate ions. There was no significant difference between the inhibition of transamination by the ADP-regenerating system with or without ADP. The regenerating system alone had no significant effect on the dehydrogenase activity. Each value represents the mean \pm S.E.M. of assays run in triplicate. *Significant effect of nucleotide: $P<0.01$.

\section{Additions \\ Concentration (mM)}

None

ATP+regenerating system for ATP

Regenerating system alone

ADP alone

ADP+regenerating system for ADP

Regenerating system alone

Adenosine $5^{\prime}-[\beta \gamma$-methylene $]$ diphosphate

Adenosine $5^{\prime}[\alpha \beta$-methylene $]$ diphosphate

Adenosine $5^{\prime}$ - $[\beta \gamma$-imido]diphosphate

Cyclic AMP

GTP

CTP

UTP $\overline{0.2}$

0.2

-

\section{2}

Activity $(\%)$

$\begin{array}{cc}\text { Dehydrogenase } & \text { Transaminase } \\ 100 & 100 \\ 16 \pm 4^{*} & 100 \pm 4 \\ 100 \pm 2 & 99 \pm 3 \\ -51 \pm 12^{*} & 85 \pm 15 \\ 100 \pm 6 & 41 \pm 10^{*} \\ 109 \pm 6 & 74 \pm 4^{*} \\ 101 \pm 2 & 56 \pm 23 \\ 93 \pm 8 & 80 \pm 9 \\ 91 \pm 6 & 100 \pm 10 \\ 93 \pm 4 & - \\ 81 \pm 9 & 103 \pm 4 \\ 93 \pm 5 & 105 \pm 3 \\ & 97 \pm 5\end{array}$

aminase was not significantly inhibited by ATP and ADP (Table 8). (For unknown reasons the ADPregenerating system and adenosine $5^{\prime}-[\beta \gamma$-methylene]diphosphate by themselves decrease leucine transamination.)

\section{Rate-limiting step for leucine degradation in intact muscles}

These studies together indicated that in muscle extracts leucine transamination occurs much more rapidly than the decarboxylation of 4-methyl-2oxopentanoate. Additional experiments were therefore performed to test whether in the intact muscle the decarboxylation of 4-methyl-2-oxopentanoate is also the rate-limiting step in the degradative pathway. If so, rat muscle incubated with $\left[{ }^{14} \mathrm{C}\right]$ leucine would be expected to accumulate or to release appreciable amounts of 4-methyl-2-oxo[ $\left[1-{ }^{14} \mathrm{C}\right]-$ pentanoate. Although the rat diaphragm or soleus muscles did not contain significant 4-methyl-2oxo $\left[1-{ }^{14} \mathrm{C}\right]$ pentanoate at the end of incubation, these muscles released this compound into the medium (Fig. 3). In fact, when leucine was present at $0.1 \mathrm{~mm}$, the rate of 4-methyl-2-oxopentanoate release approached or was similar to the rate of its decarboxylation. At 1.0 mM-leucine, 4-methyl-2-oxopentanoate release was about $30 \%$ of its rate of degradation. This result was not caused by leakage of oxo acid from the cut muscle fibres of the diaphragm, since similar or even greater 4-methyl-2-oxopentanoate production was found with the soleus muscle, which,

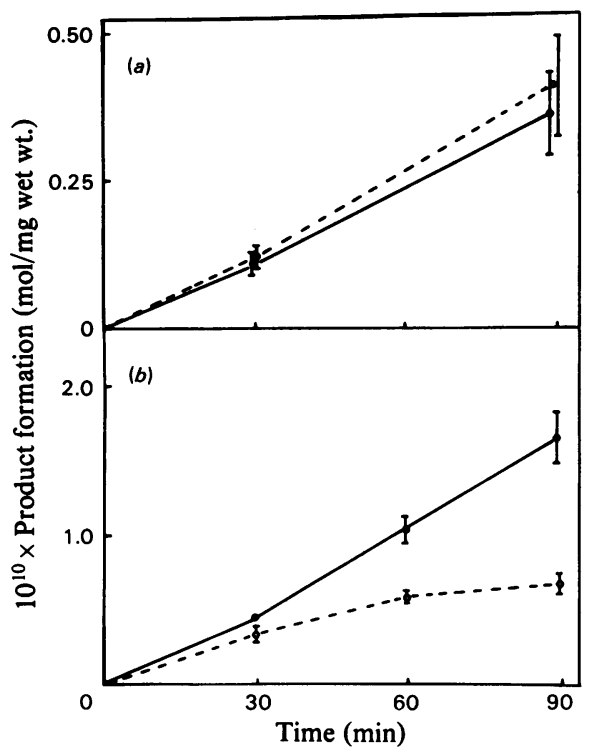

Fig. 3. Production of $\mathrm{CO}_{2}$ and 4-methyl-2-oxopentanoate from $\left[1 .{ }^{14} \mathrm{C}\right]$ leucine by incubated rat muscles

Rat quarter diaphragms $(b)$ or soleus muscles $(a)$ were incubated with $0.1 \mathrm{~mm}-\left[1-{ }^{14} \mathrm{C}\right]$ leucine as described by Odessey \& Goldberg (1972). Measurements of ${ }^{14} \mathrm{CO}_{2}$ and 4-methyl-2-oxo[1- $\left.{ }^{14} \mathrm{C}\right]$ pentanoate are described in the Materials and Methods section.,$-{ }^{14} \mathrm{CO}_{2}$ production; --.-, 4-methyl-2-oxo[1- $\left.{ }^{14} \mathrm{C}\right]$ pentanoate release. Each point represents the mean \pm S.E. of measurements from four different animals. 
unlike the diaphragm, can be removed from the animal with both tendons intact. Similarly, the production of oxo acid cannot result from leakage or secretion of an aminotransferase by the muscle since no such activity was detectable in the medium after removal of the muscle. Thus the dehydrogenase appears to be the rate-limiting step relative to the transaminase in the degradative pathway in intact muscle as in the homogenates.

Table 9. Production of ${ }^{14} \mathrm{CO}_{2}$ and $1-{ }^{14} \mathrm{C}$-labelled oxo acids from various amino acids by diaphragm

Quarter diaphragms from rats deprived of food for 2 days were incubated with $0.1 \mathrm{~mm}$-amino acids as in Fig. 3. At the end of the $90 \mathrm{~min}$ incubation, $\mathrm{CO}_{2}$ was collected (Odessey \& Goldberg, 1972). The mediumcontaining flask was resealed. The oxo acids were decarboxylated by injection of $30 \% \mathrm{H}_{2} \mathrm{O}_{2}$, and ${ }^{14} \mathrm{CO}_{2}$ was collected and counted for radioactivity, as described in the Materials and Methods section. All amino acids were studied at the same specific radioactivity. Each point represents the mean \pm S.E.M. of measurements from six different animals, and data were calculated relative to the precursor specific radioactivity in the medium. For unknown reasons, the rate of oxo acid release from the branched-chain amino acids varied appreciably on different days. NS, not significantly different from background.

\begin{tabular}{|c|c|}
\hline \multicolumn{2}{|c|}{$\begin{array}{c}10^{10} \times{ }^{14} \mathrm{C} \text { recovered }(\mathrm{mol} / \mathrm{mg} \text { of } \\
\text { muscle })\end{array}$} \\
\hline $\mathrm{CO}_{2}$ & $\begin{array}{l}1-{ }^{14} \text { C-labelled } \\
\text { oxo acid }\end{array}$ \\
\hline $\begin{array}{c}5.19 \pm 0.24 \\
2.69 \pm 0.16 \\
4.71 \pm 0.07 \\
\text { NS } \\
\text { NS } \\
\text { NS }\end{array}$ & $\begin{array}{c}0.82 \pm 0.4 \\
1.18 \pm 0.10 \\
1.20 \pm 0.16 \\
\text { NS } \\
\text { NS } \\
\text { NS }\end{array}$ \\
\hline
\end{tabular}

$$
1.91 \pm 0.24 \quad 0.49 \pm 0.014
$$

In related studies, diaphragm muscles were incubated with $\left[1-{ }^{14} \mathrm{C}\right]$ valine and $\left[1-{ }^{14} \mathrm{C}\right]$ isoleucine. After $90 \mathrm{~min}$, appreciable amounts of radioactivity were recovered in the incubation medium as the corresponding oxo acids, 2-oxoisovalerate and 3-methyl2-oxopentanoate respectively (Table 9). [Production of branched-chain oxo acids by muscles has also been observed by Shinnick \& Harper (1976) and Chang \& Goldberg (1978a).] Thus, for all three branched-chain amino acids, decarboxylation appears to be the rate-limiting enzyme in muscle. In addition, these experiments together suggest that the branched-chain oxo acids normally found in the blood (Dancis et al., 1960) are derived primarily from skeletal muscle (Table 9). For unknown reasons, the actual rate of release of the 2-oxo acids was highly variable, and in different experiments the rate of release of $1-{ }^{14} \mathrm{C}$-labelled oxo acids from the three branched-chain amino acids ranged between $15 \%$ and $47 \%$ of the rate of ${ }^{14} \mathrm{CO}_{2}$ production by diaphragms. Appreciable release of the branched chains was observed with muscles from both fed and starved rats (Table 9) in which the rate of oxo acid decarboxylation is increased.

By contrast, when the diaphragm was incubated with $\left[\mathrm{U}-{ }^{14} \mathrm{C}\right]$-tyrosine, -phenylalanine, -glycine, -serine, or-lysine, insignificant label was recovered in the medium as the respective oxo acid. These amino acids are also not converted into intermediates of the tricarboxylic acid cycle and do not undergo significant oxidation in skeletal muscle (Chang \& Goldberg, 1978a; Odessey \& Goldberg, 1972). When the muscle was incubated with $\left[1-{ }^{14} \mathrm{C}\right]$ alanine, production of $\left[1-{ }^{14} \mathrm{C}\right]$ pyruvate occurred at about one-third the rate of ${ }^{14} \mathrm{CO}_{2}$ production. [This result is in accord with the large amount of alanine transaminase in skeletal muscle (Young, 1970).]

These experiments indicate that the dehydrogenase is rate-limiting for oxidation of the branched-chain amino acids; other evidence also indicates that the dehydrogenase and not subsequent steps regulate the

Table 10. Effect of starvation on oxidation of leucine and the release of 4-methyl-2-oxopentanoate by rat diaphragm Rat quarter diaphragms were excised and incubated in Krebs-Ringer bicarbonate buffer for 90 min in the presence of leucine $(0.1 \mathrm{~mm})$ and glucose $(5 \mathrm{~mm})$ as described previously (Odessey \& Goldberg, 1972$).{ }^{14} \mathrm{CO}_{2}$ was collected after injection of $1 \mathrm{M}$-perchloric acid. After ${ }^{14} \mathrm{CO}_{2}$ was collected (Odessey \& Goldberg, 1972), the flask was restoppered and injected with $1 \mathrm{M}-\mathrm{H}_{2} \mathrm{O}_{2}$ to decarboxylate the oxo acid and the ${ }^{14} \mathrm{CO}_{2}$ was collected in like manner. Each point represents the mean \pm S.E.M. of five pieces of tissue. ${ }^{*} P<0.01$ (versus fed).

$\begin{array}{lccc}\text { Substrate } & \text { Condition } & \begin{array}{c}10^{10} \times{ }^{14} \mathrm{CO}_{2} \text { production } \\ (\mathrm{mol} / \mathrm{mg} \text { of muscle })\end{array} & \begin{array}{c}10^{10} \times{ }^{14} \mathrm{C}-\text { labelled oxo acid release } \\ (\mathrm{mol} / \mathrm{mg} \text { of muscle })\end{array} \\ {\left[1-{ }^{14} \mathrm{C}\right] \text { Leucine }} & \text { Fed } & 1.02 \pm 0.09 & 0.71 \pm 0.03 \\ \text { Ratio starved/fed } & \text { Starved } & 3.29 \pm 0.43^{*} & 0.53 \pm 0.03^{*} \\ {\left[\mathrm{U}-{ }^{14} \mathrm{C}\right] \text { Leucine }} & \text { Fed } & 3.2 & 0.75 \\ \text { Ratio starved/fed } & \text { Starved } & 0.57 \pm 0.06 & - \\ & & 2.20 \pm 0.28^{*} & -\end{array}$


rate of leucine catabolism in intact muscle. As shown previously, muscles from rats deprived of food catabolize the branched-chain amino acids more rapidly than those from fed animals (Goldberg \& Odessey, 1972; Buse et al., 1973). Table 10 shows that deprivation of food causes a 3-fold stimulation of ${ }^{14} \mathrm{CO}_{2}$ production from leucine whether it is uniformly labelled or labelled only in the carboxy group. Thus an increase in activity leading to the initial decarboxylation can account completely for the change observed. Note also that deprivation of food resulted in decreased release of $1-{ }^{14} \mathrm{C}$-labelled oxo acid, presumably due to a decrease in its intracellular concentration. The cross-over theorem (Chance et al., 1958; Rolleston, 1972) states that, for any irreversible reaction occurring in a segment of a metabolic pathway containing no branch points, regulation of that enzyme can be inferred if the flux changes in the direction opposite to that of the substrate concentration. Up to the generation of 3-hydroxy-3-methylglutaryl-CoA, the pathway of leucine degradation appears to be unbranched, and the dehydrogenase is certainly irreversible. Thus the fall in oxo acid release in muscles from animals deprived of food with an increase in leucine degradation indicates that the dehydrogenase is the regulated step.

\section{Discussion}

Skeletal muscle synthesizes de novo and releases into the circulation large amounts of the gluconeogenic precursor, alanine (Ruderman, 1975; Felig, 1975). The amino groups found in alanine are derived primarily, if not exclusively, from the branched-chain amino acids, while the carbon skeleton probably arises from pyruvate produced by muscle glycolysis (Odessey et al., 1974; Chang \& Goldberg, 1978a). The present studies suggest, however, that the amino groups released by leucine transamination are not transferred directly to pyruvate. The soluble leucine transaminase, which represents $80 \%$ of the total transaminase activity (Table 1), has a very high $K_{\mathrm{m}}(<3 \mathrm{~mm})$ for pyruvate and a low $V_{\max }$. (Table 2). Since normal pyruvate concentration in resting muscle is about $0.1 \mathrm{~mm}$ (Arese et al., 1965; Wahren et al., 1973), the rate of pyruvate transamination by this enzyme is probably negligible. Instead the catabolism of leucine probably first gives rise to glutamate via transamination with 2-oxoglutarate. The 2-oxoglutarate concentration in resting muscle is about $0.1-0.2 \mathrm{~mm}$ (Arese et al., 1965), which is about the $K_{\mathrm{m}}$ of the transaminase at physiological leucine concentrations (Table 2). The mitochondrial leucine transaminase activity also preferentially uses 2-oxoglutarate as a co-substrate (Table 3 ). These data suggest that in vivo 2-oxoglutarate is the amino acceptor for approximately $95 \%$ of the leucine transaminated in resting muscle.

Therefore the synthesis of alanine in this tissue most likely occurs by an initial transamination of leucine with 2-oxoglutarate and subsequent transamination of the resulting glutamate with pyruvate, as shown in Fig. 4. In fact, skeletal muscle has long been known to contain large amounts of glutamatepyruvate transaminase (Young, 1970). The transfer of the amino groups of valine and isoleucine to alanine probably occurs in a similar fashion, since all three branched-chain amino acids share the same transaminases (Ichihara \& Koyama, 1966; Young, 1970). In fact, addition of all the branched-chain amino acids results in an increased production of glutamate,

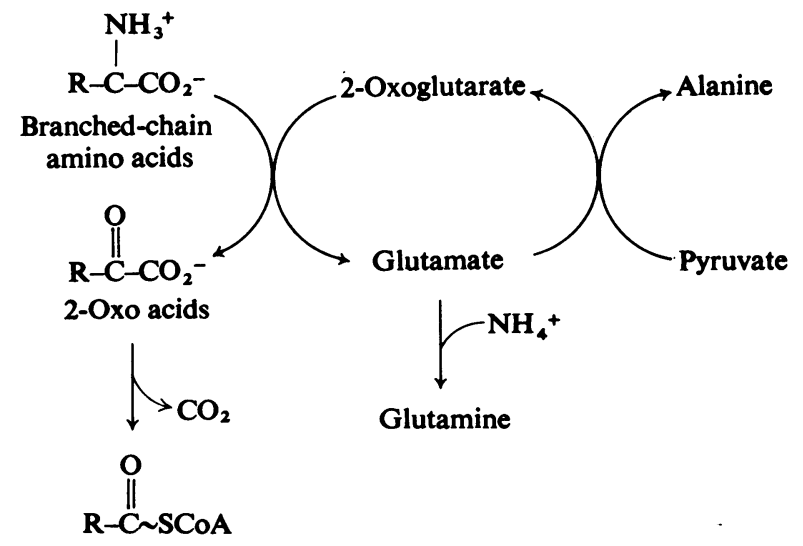

Fig. 4. Probable pathway for transfer of amino groups from branched-chain amino acids to alanine and glutamine in skeletal muscle 
which by itself can stimulate alanine production (Chang \& Goldberg, 1978a). Transamination of leucine, isoleucine and valine with 2-oxoglutarate can also account for the increased glutamine production in muscle on addition of these amino acids and the ability of $\mathrm{NH}_{4}{ }^{+}$to promote glutamine release at the expense of glutamate and alanine production (Chang \& Goldberg, 1978a; Ruderman, 1975) (Fig. 4).

Soluble and mitochondrial isoenzymes of leucine transaminase have been previously reported in pig heart (Ichihara \& Koyama, 1966; Aki et al., 1968) and rat liver (Aki et al., 1967). Results in Table 1 suggest a similar distribution in skeletal muscle. The soluble activity remained in the supernatant and its activity was not diminished after centrifugation of $150000 \mathrm{~g}$ for $60 \mathrm{~min}$, which should be sufficient to sediment any microsomal-associated enzyme. The particulate activity was associated with the mitochondrial fraction which contained $80 \%$ of the succinate dehydrogenase activity, a mitochondrial marker (Table 1). Although this assignment is not definitive in the absence of further purification of these fractions and of data on the distribution of markers for other subcellular components, the most likely conclusion from the present findings (Table 1) is that branched-chain amino acid aminotransferase in muscle exists primarily in the cytosol but also in the mitochondria. This conclusion is in accord with earlier observations (Ichihara \& Koyama, 1966; Aki et al., 1967, 1968) on the subcellular distribution of this enzyme in heart and liver, which were based on evidence similar to that obtained in Table 1.

In any case, the activity of the enzymes in both fractions is exquisitely sensitive to the concentration of free $\mathrm{Ca}^{2+}$. Table 5 shows that $0.2 \mu \mathrm{M}-\mathrm{Ca}^{2+}$, which is in the range of intracellular concentration (Ebashi \& Endo, 1968), causes a $50 \%$ inhibition, and higher concentrations can inhibit by $90 \%$. The enzyme in the particulate fraction also is stimulated 2-3-fold by removal of $\mathrm{Ca}^{2+}$ (Table 6). However, since mitochondria contain most of the cellular calcium, which is very difficult to remove from intact structures, this effect is only seen in detergent-disrupted particles. These findings raise the possibility that factors which change the intracellular calcium concentrations may affect branched-chain amino acid metabolism. For example, the findings in Table 6 predict that the rate of transamination in contracting skeletal muscle will be significantly lower than the rate in resting skeletal muscle. This possibility merits further investigation.

The present results clearly demonstrate the existence of branched-chain oxo acid dehydrogenase in extracts of skeletal muscle. Accordingly, the decarboxylation of 4-methyl-2-oxo[1-14 C]pentanoate obeyed Michaelis-Menton kinetics (Fig. 2) and required $\mathrm{NAD}^{+}, \mathrm{CoA}$ and thiamin pyrophosphate
(Table 3). The enzyme also produces stoicheiometric amounts of $\mathrm{CO}_{2}$ and isovaleryl-CoA. Furthermore, this process was inhibited by arsenite (Table 7), which binds to dihydrolipoyl residues of the dehydrogenase complexes. As substrates for the dehydrogenase, the oxo acids of all three branchedchain amino acids compete with each other (Table 4). Furthermore, the $K_{1}$ values for the oxo acids of leucine and valine are not significantly different from the $K_{\mathrm{m}}$ values. These findings are most simply accounted for by postulating a single dehydrogenase that can catalyse the decarboxylation of all three branched-chain oxo acids. This conclusion is consistent with the findings of Danner et al. (1978), who have partially purified a branched-chain oxo acid dehydrogenase from rat liver and have shown co-purification of an activity with all three oxo acids with $K_{\mathrm{m}}$ values similar to those reported in Table 4 .

Previous failures (Connelly et al., 1968; Dancis et al., 1961; Wohlheuter \& Harper, 1970; Goedde \& Keller, 1967; Johnson \& Connelly, 1968) tơ observe significant dehydrogenase activity in this tissue may have resulted from overly destructive methods of cell disruption. We have found that sonication markedly decreases dehydrogenase activity, and Sketcher et al. (1974) have reported that Polytron homogenization also destroys this activity. It should also be noted that optimal pH and cofactor concentrations for this enzyme in the muscle (Table 3 ) differ from those in the liver (Connelly et al., 1968; Wohlheuter \& Harper, 1970). Thus comparisons of enzyme activities in different tissues (Connelly et al., 1968; Wohleuter \& Harper, 1970; Goedde \& Keller, 1967; Dancis et al., 1960) under conditions optimal for the liver extracts may therefore be misleading.

Several pieces of evidence suggest that the oxidative decarboxylation of 4-methyl-2-oxopentanoate is the rate-limiting step in the oxidation of leucine by muscle. (1) Under the present conditions, the initial rate of transamination was severalfold greater than that of decarboxylation, such that 4-methyl-2-oxopentanoate built up in these homogenates (Fig. 1) and washed mitochondria. (2) At saturating substrate concentrations, the dehydrogenase was 8-fold less active than leucine transamination. (3) The addition of 2-oxoglutarate to muscle homogenates stimulated transaminase activity to a much greater extent than $\mathrm{CO}_{2}$ production from leucine (Table 3). (4) The $\mathrm{pH}$ optimum for ${ }^{14} \mathrm{CO}_{2}$ production from $\left[1-{ }^{14} \mathrm{C}\right]$ leucine in whole homogenates and washed mitochondrial pellets was identical with that found for the decarboxylation of 4-methyl-2-oxopentanoate and different from that of the transaminase reactions.

Although the relative activity of the transaminase and dehydrogenase in vivo will depend on the intracellular $\mathrm{Ca}^{2+}$ concentration, decarboxylation probably occurs more slowly than transamination in intact muscles as well. As shown in Fig. 3, diaphragm

Vol. 178 
and soleus incubated with $\left[1-{ }^{14} \mathrm{C}\right]$ leucine released amounts of 4-methyl-2-oxopentanoate comparable with the rate of ${ }^{14} \mathrm{CO}_{2}$ production. The results in Table 10 also suggest that in incubated muscles it is the dehydrogenase and not prior or subsequent steps that determine the rate of leucine degradation. Accordingly, starvation stimulates the decarboxylation of leucine to the same extent as that of the whole molecule. In addition the increased decarboxylation occurs concomitantly with a decreased release of 4-methyl-2-oxopentanoate, the substrate of the dehydrogenase. By means of the cross-over theorem, it can be inferred that regulation has occurred at the dehydrogenase step. The conclusion that the decarboxylation of 4-methyl-2-oxopentanoate is the ratelimiting step in leucine oxidation by whole muscle is also consistent with the results of others (Buse et al., 1975; Shinnick \& Harper, 1976) on rat diaphragm. These findings and our results with muscle homogenates from animals deprived of food (Odessey, 1973) do not support a report by Adibi et al. (1975) that leucine oxidation increases in starvation through enhancement of transaminase activity.

These findings emphasize the difference between liver and muscle with respect to branched-chain amino acid metabolism. Unlike in skeletal muscle, in liver transaminase activity appears to be the ratelimiting step in the degradation of the branchedchain amino acids (Dawson \& Hird, 1967; MacFarlane \& Von Holt, 1969; Shinnick \& Harper, 1976). The hepatic concentration of leucine transaminase activity is $10-20$-fold lower than it is in skeletal muscle (Young, 1970; Shinnick \& Harper 1976). The addition of transaminase stimulates leucine oxidation by liver homogenates, but not by skeletal muscle (Dawson \& Hird, 1967; Shinnick \& Harper, 1976) (Table 1). These findings are also consistent with physiological evidence that the liver plays a relatively minor role in the degradation of ingested leucine, isoleucine and valine. After a protein meal, the branched-chain amino acids account for more than $60 \%$ of the amino acids released into the circulation, although they contribute only about $20 \%$ of the amino acids ingested (Wahren et al., 1976).

Many of the properties of branched-chain oxo acid dehydrogenase demonstrated here and by others (Wohlheuter \& Harper, 1970; Goedde \& Keller, 1967) resemble those of other mitochondrial 2-oxo acid dehydrogenases such as pyruvate dehydrogenase and 2-oxoglutarate dehydrogenase. All these enzymes require $\mathrm{NAD}^{+}$, thiamin pyrophosphate and $\mathrm{CoA}$ for optimal activity and are inhibited by arsenite (Tables 3 and 7). In addition, $\mathrm{Mg}^{2+}$ and $\mathrm{Ca}^{2+}$ stimulate both branched-chain oxo acid dehydrogenase and pyruvate dehydrogenase (Table 7) (Chiang \& Sactor, 1975; Linn et al., 1969; Denton et al., 1972). It has also been found that the phosphorylation of pyruvate dehydrogenase by ATP markedly inhibits catalytic activity (Chiang \& Sactor, 1975; Linn et al., 1969). It is interesting to speculate that the branchedchain oxo acid dehydrogenase may also be regulated by phosphorylation, since the present experiments have demonstrated that ATP also inhibits this dehydrogenase (Table 8). Accordingly, none of the nonmetabolizable ATP analogues tested had any inhibitory effect (Table 8), including the imido analogue, which is sterically very similar to ATP and substitutes for ATP in many binding reactions (Yount et al., 1971). Perhaps the inability of the analogues to inhibit branched-chain oxo acid dehydrogenase results from their failure to permit phosphorylation of the dehydrogenase. This latter process may even involve the same enzyme that phosphorylates pyruvate dehydrogenase.

The existence of the phosphorylation-dephosphorylation cycle for the dehydrogenase would also be consistent with the observed ionic effects on activity. By analogy with pyruvate dehydrogenase, stimulation by $\mathrm{Mg}^{2+}$ and $\mathrm{Ca}^{2+}$ could result from an activation of the phosphatase (Linn et al., 1969; Denton et al., 1972; Seiss \& Wieland, 1972; Severson et al., 1974) or an inhibition of the kinase (Cooper et al., 1974). Also, $\mathrm{K}^{+}$may stimulate the dehydrogenase by causing an inhibition of the kinase (Roche \& Reed, 1974). Similarly, inhibition of branchedchain oxo acid dehydrogenase by NADH and isovaleryl-CoA may be due to effects on enzyme phosphorylation (Pettit et al., 1975; Hansford, 1976). Other explanations of the data are possible, and work to decide between these hypotheses deserves investigation.

This research was supported in part by U.S. Public Health Service Grant AM19120 from the National Institute of Arthritis and Metabolic Diseases to R. $\mathbf{O}$. and in part by U.S. Public Health Service Grant from the National Institute of Neurological Disease and Stroke and from the Muscular Dystrophy Associations of America to A. L. G.

\section{References}

Adibi, S. A. (1976) Metabolism 25, 1287-1302

Adibi, S. A., Peterson, S. A. \& Krzysik, B. A. (1975) Am. J. Physiol. 228, 432-435

Aki, K., Ogawa, K., Shirai, A. \& Ichihara, A. (1967) J. Biochem. (Tokyo) 62, 610-617

Aki, K., Ogawa, K. \& Ichihara, A. (1968) Biochim. Biophys. Acta 159, 276-284

Arese, P., Kirsten, R. \& Kirsten, E. (1965) Biochem. $Z$. 341, 523-533

Arrigoni, O. \& Singer, T. P. (1962) Nature (London) 193, 1256-1258

Buse, M. G. \& Reid, S.'S. (1976) J. Clin. Invest. 56, 12501261

Buse, M. G., Biggers, F., Drier, C. \& Buse, J. F. (1973) J. Boli. Chem. 248, 697-706 
Buse, M. G., Jursinic, S. \& Reid, S. S. (1975) Biochem. J. 148 363-374

Chance, B., Holmes, W., Higgins, J. J. \& Connelly, C. M. (1958) Nature (London) 182, 1190-1191

Chang, T. W. \& Goldberg, A. L. (1978a) J. Biol. Chem. 253, 3677-3684

Chang, T. W. \& Goldberg, A. L. (1978b) J. Biol. Chem. 253, 3685-3695

Chang, T. W. \& Goldberg, A. L. (1978c) J. Biol. Chem. 253, 3696-3701

Chappell, J. B. (1968) Br. Med. Bull. 24, 150-157

Chiang, P. K. \& Sactor, B. (1975) J. Biol. Chem. 250, 3399-3408

Cleland, W. W. (1967) Adv. Enzymol. 29, 1-32

Connelly, J. L., Danner, D. J. \& Bowden, J. A. (1968) J. Biol. Chem. 243, 1198-1203

Cooper, R. H., Randle, P. J. \& Denton, R. M. (1974) Biochem. J. 143, 625-641

Dancis, J., Hutzler, J. \& Levitz, M. (1960) Biochim. Biophys. Acta 43, 342-343

Dancis, J., Hutzler, J. \& Levitz, M. (1961) Biochim. Biophys. Acta 52, 60-64

Danner, D. J., Lemmon, S. K. \& Elsas, L. J., II (1978) Biochem. Med. 19, 27-38

Dawson, A. J. \& Hird, F. J. R. (1967) Arch. Biochem. Biophys. 122, 426-433

Denton, R. M., Randle, P. J. \& Martin, B. R. (1972) Biochem. J. 128, 161-163

Ebashi, S. \& Endo, M. (1968) Prog. Biophys. Mol. Biol. 18, 123-183

Felig, P. (1975) Annu. Rev. Biochem. 44, 933-954

Fink, K., Cline, R. E. \& Fink, R. M. (1963) Anal. Chem. 35, 389-398

Fulks, R., Li, J. B. \& Goldberg, A. L. (1975) J. Biol. Chem. 250, 290-2.98

Goedde, H. W. \& Keller, W. (1967) in Amino Acid Metabolism and Genetic Variation, pp. 191-218, McGrawHill, New York

Goldberg, A. L. \& Chang, T. W. (1978) Fed. Proc. Fed. Am. Soc. Exp. Biol. 37, 2301-2307

Goldberg, A. L. \& Odessey, R. (1972) Am.J. Physiol. 223, 1384-1391

Gornall, A. G., Bardawill, D. J. \& David, M. M. (1949) J. Biol. Chem. 177, 751-766

Green, D. E. \& Ziegler, D. M. (1963) Methods Enzymol. 6, 416-424

Hansford, R. G. (1976) J. Biol. Chem. 251, 5483-5489

Ichihara, A. \& Koyama, E. (1966) J. Biochem. (Tokyo) 59, 160-169

Ichihara, A., Takahashi, H., Aki, K. \& Shirai, A. (1967) Biochem. Biophys. Res. Commun. 26, 674-678
Johnson, W. A. \& Connelly, J. L. (1968) J. Biol. Chem. 243, 3526-3531

Linn, T. C., Pettit, F. R. \& Reed, L. J. (1969) Proc. Natl. Acad. Sci. U.S.A. 62, 234-241

MacFarlane, I. G. \& Von Holt, C. (1969) Biochem. J. 111, 563-571

Meister, A. (1951) J. Biol. Chem. 190, 269-276

Miller, L. L. (1961) Amino Acid Pools, pp. 708-721, Elsevier, Amsterdam

Notari, R. E. \& Munson, J. W. (1969) J. Pharm. Sci. 58, 1060-1064

Odessey, R. (1973) Ph.D. Thesis, Harvard University

Odessey, R. \& Goldberg, A. L. (1972) Am. J. Physiol. 223 , 1376-1383

Odessey, R., Khairallah, E. A. \& Goldberg, A. L. (1974) J. Biol. Chem. 249, 7623-7629

Pettit, F. H., Pelley, J. W. \& Reed, L. J. (1975) Biochem. Biophys. Res. Commun. 65, 575-582

Portzehl, H., Caldwell, P. C. \& Ruegg, J. C. (1964) Biochim. Biophys. Acta 79, 581-591

Roche, T. E. \& Reed, L. J. (1974) Biochem. Biophys. Res. Commun. 59, 1341-1348

Rolleston, F. S. (1972) Curr. Top. Cell. Regul. 5, 47-75

Ruderman, N. B. (1975) Annu. Rev. Med. 26, 245-258

Seiss, E. A. \& Wieland, O. H. (1972) Eur. J. Biochem. 26, 96-105

Severson, D. L., Denton, R. M., Pask, H. T. \& Randle, P. J. (1974) Biochem. J. 140, 225-237

Shinnick, F. L. \& Harper, A. E. (1976) Biochim. Biophys. Acta 437, 477-486

Sketcher, R. D., Fern, E. B. \& James, W. P. T. (1974) Br. J. Nutr. 31, 333-342

Solberg, H. E. \& Bremer, J. (1970) Biochim. Biophys. Acta 222, 372-380

Wahren, J., Felig, P., Havel, R. J., Jordefeldt, L., Pernow, B. \& Saltin, B. (1973) N. Engl. J. Med. 288, 774 777

Wahren, J., Felig, P. \& Hagenfelt, J. (1976) J. Clin. Invest. 57, 987-999

Wieland, T. \& Fischer, E. (1949) Naturwissenschaften 36, 219

Wohlheuter, R. M. \& Harper, A. E. (1970) J. Biol. Chem. 245, 2391-2401

Young, V. R. (1970) in Mammalian Protein Metabolism (Munro, H. N., ed), vol. 4, pp. 586-674, Academic Press, New York

Yount, R. G., Babcock, D., Ballantyne, W. \& Ojala, D. (1971) Biochemistry 10, 2484-2489

Zak, R., Etlinger, J. \& Fischman, D. A. (1970) Excerpta Med. Found. Int. Congr. Ser. no. 240: Research in Muscle Development and the Muscle Spindle, pp. 163-135 